\title{
Extended kinetic method and RRKM modeling to reinvestigate proline's proton affinity and approach the meaning of effective temperature.
}

\author{
Denis Lesage, ${ }^{1 *}$ Sakina Mezzache, ${ }^{1}$ Yves Gimbert, ${ }^{1,2}$ Héloïse \\ Dossmann, ${ }^{1}$ Jean-Claude Tabet ${ }^{1,3}$. \\ ${ }^{1}$ Sorbonne Université, CNRS, Institut Parisien de Chimie Moléculaire, IPCM, 75005 Paris, \\ France. Email: denis.lesage@sorbonne-universite.fr \\ ${ }^{2}$ Univ. Grenoble Alpes and CNRS, DCM (UMR 5250) BP 53, 38041 Grenoble Cedex 9, \\ France.
}

3 Service de Pharmacologie et d'Immunoanalyse (SPI), Laboratoire d'Etude du Métabolisme des Médicaments, CEA, INRA, Université Paris Saclay, MetaboHUB, F91191 Gif-sur-Yvette, France.

\section{Abstract}

Proline proton affinity PA(Pro) was previously measured by extended kinetic methods with several amines as reference bases using a triple quadrupole mass spectrometer (J Mass Spectrom 2005; 40: 1300). The measured value of $947.5 \pm 5 \mathrm{~kJ} \mathrm{~mol}^{-1}$ differs by more than $10 \mathrm{~kJ} \mathrm{~mol}^{-1}$ from previous reported experimental or calculated values. This difference may be explained in part by the existence of relatively large entropy difference between the two dissociation channels $\left(\Delta \Delta \mathrm{S}^{+}\right.$avg $\left.=31 \pm 10 \mathrm{~J} \mathrm{~mol}^{-1} \cdot \mathrm{K}^{-1}\right)$ and by the inaccuracy of the amines proton affinity used as reference bases. In the present work, these experimental measurements were reinvestigated by RRKM modeling using MassKinetics software. From this modeling, a new PA value of $944.5 \pm 5 \mathrm{~kJ} \mathrm{~mol}^{-1}$ and a $\Delta \Delta \mathrm{S}^{\dagger}$ avg(600K) value of 33 $\pm 10 \mathrm{~J} . \mathrm{mol}^{-1} \cdot \mathrm{K}^{-1}$ are determined. However, the difference between experiment and recent theoretical calculations remains large $\left(10 \mathrm{~kJ} \mathrm{~mol}^{-1}\right)$. These RRKM simulations allow also accessing to the effective temperature parameter $\left(\mathrm{T}_{e f f}\right)$ and to discuss the meaning of this term. As previously reported, $\mathrm{T}_{\text {eff }}$ mainly depends on the internal energy and on the decomposition time as well. It also depends on the critical energies and on the transition state. Considering the entrance of the collision cell as a new ion source, $\mathrm{T}_{\text {eff }}$ is finally shown to be close to a characteristic temperature $\left(\mathrm{T}_{\text {char }}\right)$.

\section{Keywords}

Effective temperature; Kinetic method; proton affinity; entropy; internal energy; RRKM; MassKinetics software 


\section{Introduction}

In mass spectrometry, the notion of temperature is often used to describe the internal energy of an ion population. Different terms are found in the literature to refer to a temperature, such as thermodynamic $(\mathrm{T})$, characteristic $\left(\mathrm{T}_{\text {char }}\right)$, collisional $\left(\mathrm{T}_{\text {coll }}\right)$, effective $\left(\mathrm{T}_{\text {eff }}\right)$, etc., all describing different conditions of excitation and/or decomposition of the ions. The real thermodynamic temperature $(\mathrm{T})$ characterized by a Maxwell-Boltzmann distribution is reached in blackbody infrared radiative dissociation (BIRD) activation technique. ${ }^{1-3}$. In BIRD the condition for the ions to be at thermal equilibrium at $\mathrm{T}$ during the entire measurement is only realized for large ions which reach the limit conditions of rapid energy exchange (REX limit). ${ }^{3,4}$ These REX limit conditions are also achieved in the case of very soft collisional activation leading to a Maxwell-Boltzmann internal energy distribution at equilibrium. In this case, the term "effective temperature" "thermal collisional temperature" term would be more adequate to avoid any ambiguity with the $\mathrm{T}_{\text {eff }}$ term used for the kinetic method (discussed later). ${ }^{8}$ For smaller systems, the highest energy part of the Maxwell-Boltzmann distribution is truncated and one speaks accordingly about truncated or depleted thermal distribution at equilibrium. Under these conditions, obtaining thermodynamic data requires a more complex kinetic modeling using Master Equation Modeling ${ }^{3,4}$ based on the Lindemann-Hinshelwood model. ${ }^{9}{ }^{10}$ This model, first developed for collisional activation of an $\mathrm{AB}^{+}$ion on a neutral $\mathrm{M}$, separates the bimolecular activation $\left(k_{1, \text { coll }}\right)$ and $\left(k_{-1, \text { coll }}\right)$ deactivation processes to form an activated species $\mathrm{AB}^{+*}$ which may decomposed by unimolecular processes $\left(k_{\mathrm{d}}\right)$ (Scheme 1$)$.

$$
\mathrm{AB}^{+}+\mathrm{M} \underset{k_{-1, \text { coll }}}{\stackrel{k_{1, \text { coll }}}{\longrightarrow}} \mathrm{AB}^{+*} \stackrel{k_{\mathrm{d}}}{\longrightarrow} \mathrm{A}^{+}+\mathrm{B}
$$

Scheme 1. The three fundamental processes considered in the Lindemann-Hinshelwood model.

In the case of BIRD, this model takes into account the competition of three rate constants of IR absorption and emission and unimolecular decomposition of the ion, ${ }^{4}$ these rate constants being described by Einstein absorption and spontaneous emission law and by RRKM-QET (Rice Ramsperger Kassel Marcus-Quasi-Equilibrium Theory) formalism. ${ }^{11}$, 12

Also based on this model, the non-equilibrium truncated Maxwell-Boltzmann distribution is often used to describe the ion temperature ${ }^{9}$ that De Pauw, Vékey and coworkers introduced as a characteristic temperature $\left(\mathrm{T}_{\text {char }}\right){ }^{13,}{ }^{14} \mathrm{In}$ this case, the rate of deactivation is negligible and activation and fragmentation are considered as consecutive steps. This $\mathrm{T}_{\text {char }}$ thus corresponds to a thermodynamic temperature reached very rapidly by the ions prior to their slow decomposition after activation. This model is used to describe the fast activation processes that take place via multiple collisions in different API (Atmospheric Pressure Ionization) sources. ${ }^{13-21}$ It is also used for multiple collisions taking place in a triple quadrupole collision cell operating under high pressure conditions ${ }^{22,23}$ or in the higher-energy collisional (HCD) cell of an orbitrap spectrometer. ${ }^{24}$ Finally it is also used to describe the ions produced by laser desorption in different techniques. ${ }^{25-27}$ 
A third temperature, named effective temperature $\left(\mathrm{T}_{\text {eff }}\right)$, was introduced in the kinetic method which will be presented in more details below. While thermodynamic, equilibrium truncated Maxwell-Boltzmann and characteristic temperatures are quite easy to define by internal energy distributions and their evolution over time, an effective temperature as it is described in the kinetic method ${ }^{8,28}$ is much more complex to conceptualize (Fig. 1).
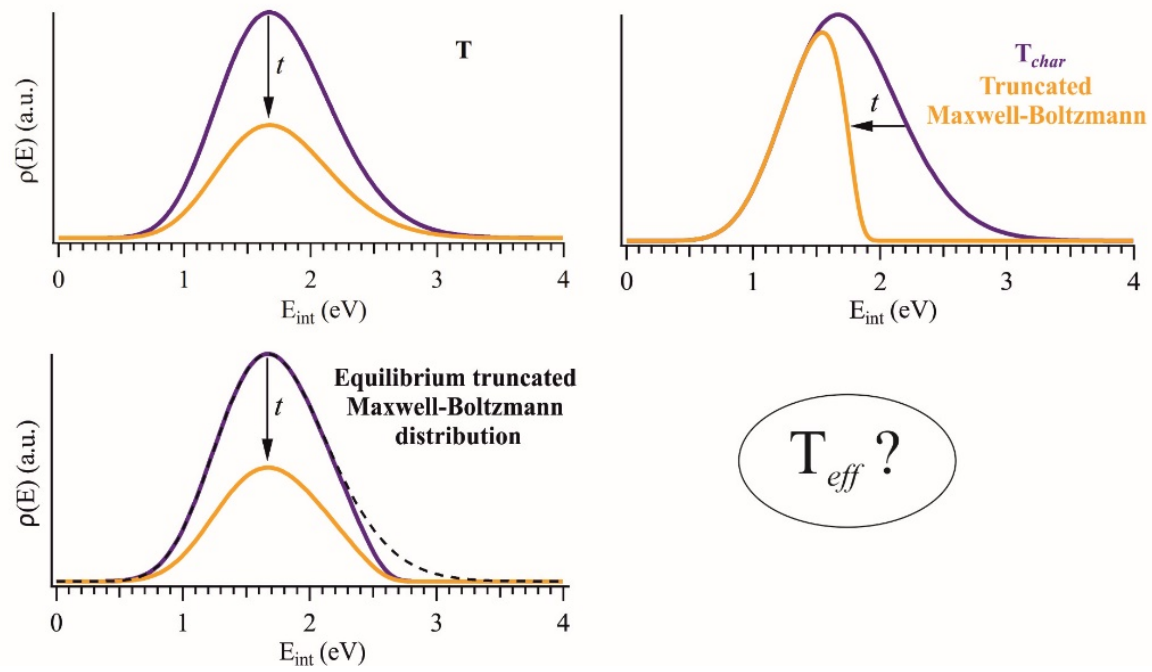

Figure 1. Different temperatures used in MS and evolution of the corresponding internal energy distributions with time.

One of the most widely used experimental approaches to determine the thermochemical data such as basicities and acidities is the kinetic method developed by Cooks et al. more than 40 years ago. ${ }^{8,28,29}$ Other technics such as the "equilibrium method" 30 or the "thermokinetic method" are also available, but they are slow and less easily applied compared to the kinetic method and hence justify the importance of understanding the quality of the kinetic method data and its related effective temperature parameter.

Determining proton affinities (PA) using the kinetic method consists in comparing the $k_{0}$ and $k_{\mathrm{i}}$ relative rate constants of the competitive dissociations of selected hydrogen-bound heterodimers $\left[\mathrm{B}_{0} \mathrm{H}^{+} \mathrm{B}_{\mathrm{i}}\right]$ where $\mathrm{B}_{0}$ is a base with an unknown proton affinity value, $\mathrm{PA}\left(\mathrm{B}_{0}\right)$, and $\mathrm{B}_{\mathrm{i}}$, one with a known proton affinity value, (Scheme 2 ).

$$
\left[\mathrm{B}_{0} \mathrm{H}^{+} \mathrm{B}_{\mathrm{i}}\right] \stackrel{k_{i}}{\longrightarrow} \mathrm{B}_{0}+\mathrm{B}_{\mathrm{i}} \mathrm{H}^{+}
$$

Scheme 2. The two competitive dissociation pathways of hydrogen-bound heterodimers $\left[\mathrm{B}_{\mathrm{o}} \mathrm{H}^{+} \mathrm{B}_{\mathrm{i}}\right]$.

One fundamental assumption of this method is that the $k_{\mathrm{i}} / k_{\mathrm{o}}$ ratio is approximately equal to the $\mathrm{I}\left(\mathrm{B}_{\mathrm{i}} \mathrm{H}^{+}\right) / \mathrm{I}\left(\mathrm{B}_{0} \mathrm{H}^{+}\right)$abundance ratio obtained by $\mathrm{MS} / \mathrm{MS}$ experiments. This ratio is directly related to the proton affinity of both product ions and $\mathrm{T}_{\text {eff }}$ following Arrhenius law (Equ. 1).

$\ln \left(\mathrm{k}_{\mathrm{i}} / \mathrm{k}_{\mathrm{o}}\right) \approx \ln \left[\mathrm{I}\left(\mathrm{B}_{\mathrm{i}} \mathrm{H}^{+}\right) / \mathrm{I}\left(\mathrm{B}_{0} \mathrm{H}^{+}\right)\right]=\left[\mathrm{PA}\left(\mathrm{B}_{\mathrm{i}}\right)-\mathrm{PA}\left(\mathrm{B}_{\mathrm{o}}\right)\right] / \mathrm{RT}_{e f f}$ 
Under particular experimental conditions, $\ln \left[\mathrm{I}\left(\mathrm{B}_{\mathrm{i}} \mathrm{H}^{+}\right) / \mathrm{I}\left(\mathrm{B}_{0} \mathrm{H}^{+}\right)\right]$shows a linear dependence to $\mathrm{PA}\left(\mathrm{B}_{\mathrm{i}}\right)$, characterized by a $1 / \mathrm{RT}_{\text {eff }}$ slope and a $\mathrm{PA}\left(\mathrm{B}_{\mathrm{o}}\right) \mathrm{x}$-intercept. This method is based on different approximations discussed by Cooks ${ }^{28}$ and Armentrout, ${ }^{31}$ the most criticized one being the neglect of the entropic effects. This method indeed requires the use of reference bases which have the same chemical function group as the studied compound. Different methods proposed by Fenselau and co-workers ${ }^{32}$ and later improved by Armentrout, ${ }^{33}$ called extended kinetic methods (or full entropy kinetic methods) may be used to consider and to determine the $\Delta\left(\Delta \mathrm{S}^{\ddagger}\right)$ value for the studied partner pair, $\Delta\left(\Delta \mathrm{S}^{\ddagger}\right)$ being the activation entropies difference between the transition states of fragmentation channels and not the entropy difference for the products. When this $\Delta\left(\Delta \mathrm{S}^{\ddagger}\right)$ term is not equal to 0 , the measured PA value may change with the effective temperature. In such case, this measured value is then called the "apparent basicity" (i.e., GB ${ }^{\text {app }}$ ). ${ }^{34}$ The experimental parameter generally used to vary the effective temperature is the collision energy (or laboratory energy, denoted $\mathrm{E}_{\mathrm{lab}}$ ). Thus, these extended kinetic methods ${ }^{32,33}$ employed the following approximation (Equ. 2):

$\mathrm{GB}^{\mathrm{app}}\left(\mathrm{B}_{\mathrm{o}}\right)=\operatorname{PA}\left(\mathrm{B}_{\mathrm{o}}\right)-\mathrm{T}_{\text {eff }} \Delta \Delta \mathrm{S}_{\mathrm{avg}}^{+}$

with $\Delta \Delta \mathrm{S}_{\text {avg }}^{\ddagger}=\Delta\left(\Delta \mathrm{S}^{\ddagger}\right)=\Delta \mathrm{S}^{\ddagger}\left(\mathrm{B}_{\mathrm{i}} \mathrm{H}^{+}\right)-\Delta \mathrm{S}^{\ddagger}\left(\mathrm{B}_{0} \mathrm{H}^{+}\right)$

In these methods, the reference bases $B_{i}$ are chosen or assumed to have an approximately constant $\Delta \mathrm{S}^{\ddagger}\left(\mathrm{B}_{\mathrm{i}} \mathrm{H}^{+}\right)$value for the reaction $k_{i}$ (the average $\Delta\left(\Delta \mathrm{S}^{\ddagger}\right)$, denoted here $\Delta \Delta \mathrm{S}^{\ddagger}{ }_{\text {avg }}$, is then defined). Note that $\Delta\left(\Delta \mathrm{S}^{\ddagger}\right)$ may differ from the difference of the entropy changes of protonation (it is usually smaller for a high $\mathrm{T}_{\text {eff }}$ of excitation).

It is well known that $\mathrm{T}_{\text {eff }}$ is an empirical parameter and is not a true thermodynamic temperature (because ions are not in thermal equilibrium), hence $\Delta \Delta \mathrm{S}^{\ddagger}$ avg cannot be correct. Instead, the term "apparent entropy difference, $\Delta \Delta \mathrm{S}^{\dagger}$ app" is sometimes used. ${ }^{35}$ From Equ. 2 , it appears therefore crucial to determine how $\mathrm{T}_{\text {eff }}$ differs from $\mathrm{T}$. As a consequence, one of the most animated discussions of the past years was centered on the feasibility to determine enthalpy and entropy differences by the extended kinetic methods. To answer this question, Drahos and Vékey ${ }^{36}$ have undertaken a study on the rigorous simulations of kinetic method experiments from the RRKM-based MassKinetics software. ${ }^{37}$ The aim of this study was to calculate theoretical CID (Collision-Induced Dissociation) spectra, based on known thermochemical parameters and as a function of experimental conditions. In agreement with other theoretical works, ${ }^{38-46}$ their conclusions show that the extended kinetic method introduced by Fenselau and co-workers provides accurate relative energetics for competitive reactions. Nevertheless, depending on the $\Delta \Delta \mathrm{S}^{\ddagger}$ avg value, the use of the extended kinetic method may give inaccurate $\Delta \Delta \mathrm{S}^{*}$ avg and eventually inaccurate PA measurements. ${ }^{36,40,41,43}$ As reported, small systems appear to lead to problematic situation. Moreover, large $\Delta \Delta \mathrm{S}^{\dagger}$ avg values and especially negative values $\left(>35 \mathrm{~J} \cdot \mathrm{mol}^{-1} \cdot \mathrm{K}^{-1}\right.$ or $<-15$ J.mol ${ }^{-1} \cdot \mathrm{K}^{-1}$ ) are also difficult systems to handle. ${ }^{36,41,43}$ They are characterized by nonlinear "kinetic plots" 40 which complicate accurate extrapolations, especially for the higher energies of excitation. Thus, large overall errors (standard deviations) are reported for the extended kinetic method measurements. ${ }^{38,41,43}$ It should be emphasized that these reported 
errors significantly depend on the size of the studied system and they cannot be avoided by more precise experiments. ${ }^{41,43}$

Another related debate concerns the effective temperature meaning. As shown by Drahos and Vékey, ${ }^{47}$ the effective temperature may be characterized by the decomposing precursor ion population, by molecular parameters and by the experimental time windows. They found a very good correlation between $\mathrm{T}_{\text {eff }}$ and the mean internal energy of ions dissociating in the time window of analysis. Using microcanonical description, the meaning of effective temperature parameter in the kinetic method has been extensively discussed by Ervin. ${ }^{42}$ Thus, internal energy distributions of decomposing precursor ion populations and $\mathrm{T}_{\text {eff }}$ values were also discussed from different numerical simulations where $\left(\mathrm{E}_{0(1)}+\mathrm{E}_{0(2)}\right) / 2$, DOF (degree of freedom), decomposition time, source temperature and preexponential factor are varying parameters. For Laskin and Futrell, ${ }^{44}$ the effective temperature closely resembles the average value of the transition state temperature $\left(\mathrm{T}^{*}\right)$. The possible existence of two transitions state temperatures is also mentioned. Although these studies are based either on metastable decomposition or on defined decomposition energies, they allow however predicting coherent effective temperature properties.

In this work, we propose to approach the meaning of the effective temperature by using a model system, proline, whose basicity was studied in one of our previous work. ${ }^{48}$ To this end, we will first confront the thermodynamical data (i.e., PA and $\Delta \Delta \mathrm{S}^{\ddagger}$ avg) values obtained experimentally and theoretically (from the MassKinetics software) Then, the effective temperatures obtained from these simulations will be compared to Maxwell-Boltzmann type internal energy distributions.

This example was chosen because the measured experimental value of the proton affinity for the proline $\left(\mathrm{PA}(\mathrm{Pro})=947.5 \pm 5 \mathrm{~kJ}^{\mathrm{m} \mathrm{mol}^{-1}}\right)^{48}$ differs from reported experimental

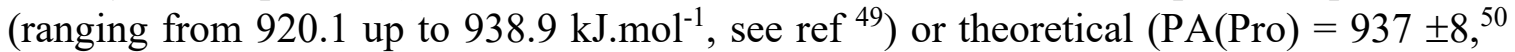
$931.8,{ }^{51} 935.0$ and $934.1^{52}$ and $935.1 \mathrm{~kJ} \mathrm{~mol}^{-1}$ in this work) values. This difference may be certainly explained by the existence of large entropy difference between the two dissociation channels $\left(\Delta \Delta \mathrm{S}_{\text {avg }}^{\ddagger}=31 \pm 10 \mathrm{~J}_{\mathrm{mol}}{ }^{-1} \cdot \mathrm{K}^{-1}\right)$. Because of this large $\Delta \Delta \mathrm{S}^{\ddagger}$ avg value, $\mathrm{T}_{\text {eff }}$ is playing a major role discussed in this work.

\section{Methods}

\section{Studied molecules}

The proton affinity values of the reference bases used (pyridine, cyclohexylamine, 3picoline, 4-vinylpyridine, 4-picoline and pyrrolidine), noted $\mathrm{PA}\left(\mathrm{B}_{\mathrm{i}}\right)$, are reported in supplementary material (Table S1). They are monofunctional systems and thus, ideal reference bases because their gas phase properties are well-known.

\section{Mass spectrometry}

Experimental results and mass spectrometry conditions have been previously published. ${ }^{48}$

\section{Theoretical methods}


Kinetic modeling was performed using the MassKinetics Scientific Demo software. ${ }^{37}$, ${ }^{53}$ Internal energy-dependent reaction rates were calculated by transition state theory (RRKM formalism).

Besides kinetic modeling, electronic structure calculations were also performed using the Gaussian 09 software package ${ }^{54}$ in order to evaluate PA(Pro) and also obtain the frequency set and the critical energies $\left(\mathrm{E}_{0}\right)$ of the [Pro $\mathrm{H}^{+} \mathrm{Pyr}$ ] heterodimer ion. To this end, the composite G4 method ${ }^{55}$ was chosen to calculate PA(Pro) as it is known to provide high accuracy thermochemical data. The other set of data were obtained at the B3P86/6-31+G* level which was a good compromise between calculation time and accuracy. Detailed results of calculations are given in the supplementary material.

\section{Results and discussion}

In our previous study, ${ }^{48}$ the proton affinity of proline and the entropy difference between the formation of protonated proline and protonated amine references, applying the

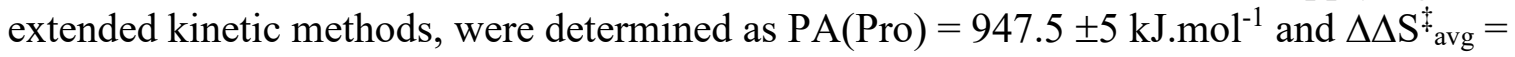
$31 \pm 10 \mathrm{~J} \cdot \mathrm{mol}^{-1} \cdot \mathrm{K}^{-1}$. In the present work, these thermochemical data are reinvestigated by RRKM modeling of the "alternative method" proposed by Armentrout ${ }^{33}$ and the “isothermal point" or "isokinetic point" developed by Bouchoux and co-workers. ${ }^{56}$

\section{MassKinetics approach for the kinetic method studies.}

For the [Pro $\mathrm{H}^{+} \mathrm{Pyr}$ ] heterodimer, the "concentration" of the precursor ion and the concentration of the two competitive $\mathrm{ProH}^{+}$and $\mathrm{PyrH}^{+}$product ions, calculated at different points of the mass spectrometer using MassKinetics software, are reported in the supporting information (Fig S1). The corresponding internal energy distributions of the precursor ion for each stage of the mass spectrometer are also shown.

\section{Fit of the experimental results using the proposed model}

\section{Main considerations about the studied system}

The calculated intensity ratios of the two monomers $\left(\mathrm{ProH}^{+}\right.$and $\left.\mathrm{B}_{\mathrm{i}} \mathrm{H}^{+}\right)$are obtained after optimization of i) the assumed "thermal-like" internal energy distribution of ions leaving the electrospray source, ii) the intrinsic thermo-kinetic properties of the studied system ( $\Delta \mathrm{PA}, \mathrm{E}_{0}, \Delta \Delta \mathrm{S}^{\ddagger}$ avg,$\Delta \mathrm{S}^{\ddagger}$ ) and iii) the collisional parameters (number of collisions, efficiency of collision). These three points are discussed below.

i) From the approach of Vékey and co-workers, ${ }^{14}$ which was here slightly modified, a calibration of the mean internal energies $\left\langle\mathrm{E}_{\text {int }}\right\rangle$ as a function of the cone voltage $\left(\mathrm{V}_{\mathrm{c}}\right)$ and source temperature $(\mathrm{T})$ of our triple quadrupole has been proposed ${ }^{15}$ (Equ. 3). In this equation the $E_{\text {therm }}(T)$ is the mean internal energy due to the source temperature at $0 \mathrm{~V}$ cone voltage.

$<\mathrm{E}_{\text {int }}>=\left[405 \times 10^{-6}-480 \times 10^{-9}(\mathrm{DOF})\right] \mathrm{V}_{\mathrm{c}} \mathrm{T}+\mathrm{E}_{\text {therm }}(\mathrm{T})$ 
For the studied system [Pro $\mathrm{H}^{+} \mathrm{B}_{\mathrm{i}}$ ], a mean internal energy of $1.75 \mathrm{eV}$ is estimated, which corresponds to a characteristic temperature of $\mathrm{T}_{\text {char }}=700 \mathrm{~K}$. Note that in a Quattro I mass spectrometer ions are not thermalized in the transfer hexapole $\mathrm{H} 0$ due to a low pressure in this region. Furthermore, calculated abundances of the product ions formed in the source cannot be compared to experimental results measured in MS mode because protonated monomer species $\left(\mathrm{ProH}^{+}\right.$and $\left.\mathrm{BiH}_{\mathrm{i}}^{+}\right)$are also present in the source with large excess and with unknown concentrations. Therefore, in this case, the "survival yield" method described by Vékey and co-workers ${ }^{14}$ cannot be used for the $\mathrm{T}_{\text {char }}$ measurement.

ii) Hypothetical microcanonical rate-energy dependency curves "log k.s vs. Eint", for the $\left[\mathrm{Pyr} \mathrm{H}^{+} \mathrm{Pro}\right]$ dimer, are reported in Fig. 2. A cross point is expected in this case because an inversion of the $\mathrm{PyrH}^{+} / \mathrm{ProH}^{+}$ratio was observed for CID processes. ${ }^{48}$ It is obvious that calculation of these curves depends on the thermodynamical data used $\left(\mathrm{E}_{0}\right.$ and $\left.\Delta \mathrm{S}^{\ddagger}\right)$. These data cannot be measured using the extended kinetic methods, and only relative values $\left(\Delta \mathrm{E}_{0}\right.$ and $\Delta \Delta \mathrm{S}^{*}$ avg) may be accessed.

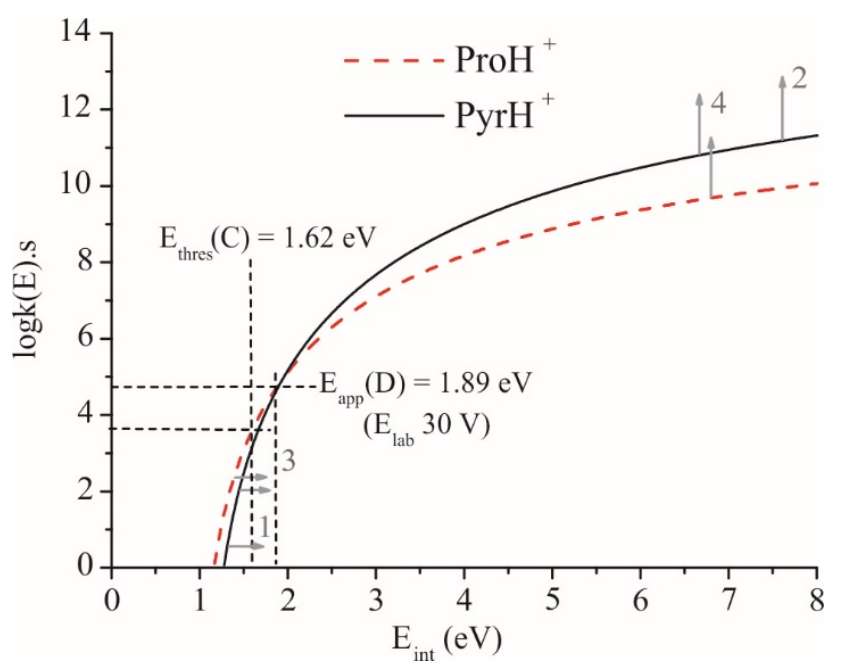

Figure 2. Hypothetical microcanonical rate-energy dependencies for protonated prolinepyridine heterodimer. The modification of the four major parameters discussed in the text and in the supplementary material is reported on these curves with the gray arrows: (1) the difference of critical energies $\left(\Delta \mathrm{E}_{0}\right),(2)$ the difference of activation entropies $\left(\Delta \Delta \mathrm{S}^{\ddagger a v g}\right)$, (3) the initial value used for the critical energy $\left(\mathrm{E}_{0}\right)$ and (4) the initial value used for the activation entropy $\left(\Delta S^{\ddagger}\right)$.

It is noteworthy that no reverse activation energy was assumed in the reaction pathway, and thus the dissociation energy was close to the critical energy of fragmentation. The critical energy of the reaction leading to the formation of protonated proline is first set at $\mathrm{E}_{0}\left(\mathrm{ProH}^{+}\right)=1.0 \mathrm{eV}$. Thus, the critical energy of the alternative reaction channel (formation of the protonated amine) is expressed in Equ. 4 where $\left[\Delta \Delta \mathrm{H}_{298 \mathrm{~K}}-\Delta \Delta \mathrm{H}_{0 \mathrm{~K}}\right]$ is the thermal enthalpy correction because $\mathrm{E}_{0}$ are defined at $0 \mathrm{~K}$ and $\mathrm{PA}$ are measured from reference bases at $298 \mathrm{~K}$.

$$
\mathrm{E}_{0}\left(\mathrm{~B}_{\mathrm{i}} \mathrm{H}^{+}\right)=\mathrm{E}_{0}\left(\mathrm{ProH}^{+}\right)-\left\{\left[\mathrm{PA}\left(\mathrm{B}_{\mathrm{i}}\right)-\mathrm{PA}(\mathrm{Pro})\right]+\left[\Delta \Delta \mathrm{H}_{298 \mathrm{~K}}-\Delta \Delta \mathrm{H}_{0 \mathrm{~K}}\right]\right\} / 96.485
$$


The pre-exponential factor for the reaction leading to the formation of protonated amine is first set to $\mathrm{A}\left(\mathrm{B}_{\mathrm{i}} \mathrm{H}^{+}\right)=10^{15} \mathrm{~s}^{-1}\left(\Delta \mathrm{S}^{\ddagger}\left(\mathrm{B}_{\mathrm{i}} \mathrm{H}^{+}\right)_{(600 \mathrm{~K})}=26 \mathrm{~J} \cdot \mathrm{mol}^{-1} \cdot \mathrm{K}^{-1}\right)$ for this direct bond cleavage. The transition state frequencies are those proposed by default by MassKinetics software (the reaction coordinate frequency is $1200 \mathrm{~cm}^{-1}$ and the $800,800,600,600,100$ $\mathrm{cm}^{-1}$ frequencies were changed into $395,395,329,329$ and $49 \mathrm{~cm}^{-1}$, respectively). A detailed investigation of the transition state frequencies as it was done previously ${ }^{18,46,57}$ is out of the scope of this paper. So, a large inaccuracy will be considered for $\Delta \mathrm{S}^{\ddagger}$ values.

iii) First, the efficiency of collision is chosen equal to 0.3 . The average number of collisions is set at 1.1 to fit the survival yield observed in the Q3 analyzer.

Table 1. Parameters used to obtain the best fitting of MassKinetics calculations.

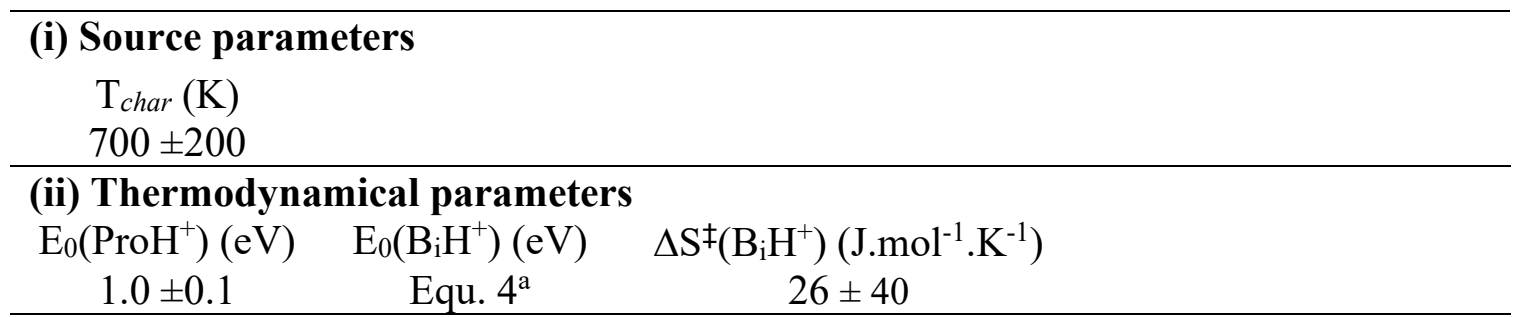

(iii) Collisional parameters

Average number of collisions Efficiency of collision $1.1(0.2$ to 5$)$ $0.3 \pm 0.15$

$\overline{{ }^{a} \mathrm{E}_{0}\left(\mathrm{ProH}^{+}\right)-\left\{\left[\mathrm{PA}\left(\mathrm{B}_{\mathrm{i}}\right)-\mathrm{PA}(\mathrm{Pro})\right]+\left[\Delta \Delta \mathrm{H}_{298 \mathrm{~K}}-\Delta \Delta \mathrm{H}_{0 \mathrm{~K}}\right]\right\} / 96.485 \text {. For these thermodynamical parameters }}$

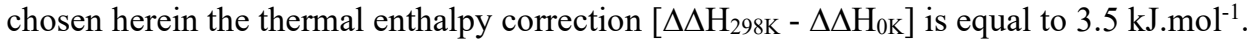

Ion abundances obtained from experimental and simulated mass spectra are used to plot $\ln \left[\left(\mathrm{B}_{\mathrm{i}} \mathrm{H}^{+}\right) /\left(\mathrm{ProH}^{+}\right)\right.$vs. $\mathrm{PA}\left(\mathrm{B}_{\mathrm{i}}\right)$ curves for different laboratory energies $\left(\mathrm{E}_{\text {lab }}\right)$. The best simulation is obtained with PA(Pro $)=944.5 \mathrm{~kJ} \cdot \mathrm{mol}^{-1}$ and $\Delta \Delta \mathrm{S}_{\text {avg }}^{\ddagger}=33 \mathrm{~J} \cdot \mathrm{mol}^{-1} \cdot \mathrm{K}^{-1}$. Note that for these conditions, $\mathrm{PA}(\mathrm{Pro})$ is $3 \mathrm{~kJ}^{\mathrm{mol}}{ }^{-1}$ smaller than the experimental value and $\Delta \Delta \mathrm{S}_{\text {avg }}^{\ddagger}$ is $2 \mathrm{~J} \cdot \mathrm{mol}^{-1} . \mathrm{K}^{-1}$ higher. All the different parameters used to carry out these simulations are reported in Table 1. The experimental and calculated curves are proposed in Fig. 3(a) and 3(b), respectively. These different plots cross at a common point called "isokinetic point" which allows to obtain the $\Delta \Delta \mathrm{S}^{\ddagger}$ avg and PA(Pro) values. These values can also be obtained using Armentrout's alternative method and then the calculated and experimental plots $\mathrm{GB}^{\text {app }} v s$. $\mathrm{T}_{\text {eff }}$ are shown in Fig. 4. However, in the case of nonlinear effects that can be obtained with the kinetic method, resulting from intrinsic properties of the systems investigated and artifacts resulting from experimental issues, it is shown that orthogonal distance regression $(\mathrm{ODR})^{58}$ analysis of kinetic method data provides the optimum way of acquiring accurate thermodynamic information. ${ }^{46}$ 
(a)

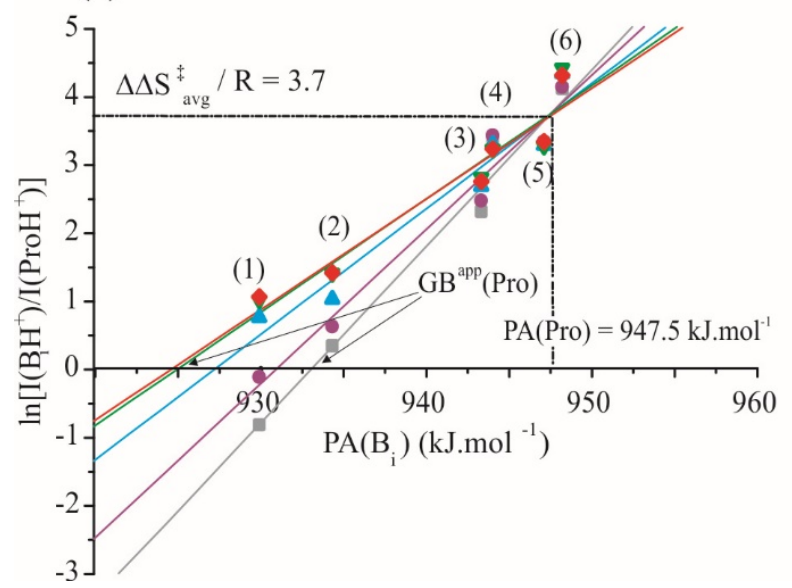

(b)

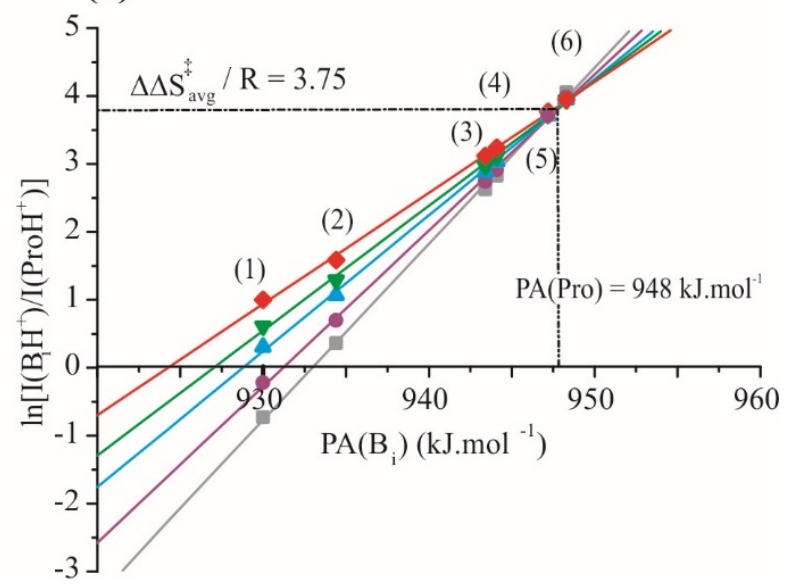

Figure 3. (a) experimental plot of " $\ln \left[\mathrm{I}\left(\mathrm{B}_{\mathrm{i}} \mathrm{H}^{+}\right) / \mathrm{I}\left(\mathrm{ProH}^{+}\right)\right]$vs. $\mathrm{PA}\left(\mathrm{B}_{\mathrm{i}}\right)$ " determined for

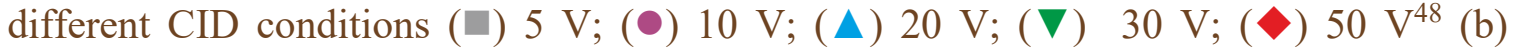
corresponding calculated plots of " $\ln \left[\mathrm{I}\left(\mathrm{B}_{\mathrm{i}} \mathrm{H}^{+}\right) / \mathrm{I}\left(\mathrm{ProH}^{+}\right)\right]$vs. $\mathrm{PA}\left(\mathrm{B}_{\mathrm{i}}\right)$ " obtained using MassKinetics software (parameters Table 1 are used for calculation). Fig. 3(a) Adapted with permission from J Mass Spectrom 2005; 40: 1300. Copyright 2005 Wiley.

Moreover, note that the calculated point for $1 \mathrm{~V}$ collision voltage (which is not accessible experimentally) confirms the non-linearity of the curve $\mathrm{GB}^{\text {app }} v s$. $\mathrm{T}_{\text {eff. The }}$ theoretical point for $\mathrm{T}_{\text {eff }}=0 \mathrm{~K}$ (PA value introduced in the software) and a polynomial fit are added on the Fig. 4 . Thus, this non-linearity might explain the $3 \mathrm{~kJ} \mathrm{~mol}^{-1}$ difference between the experimental and the theoretical PA values.

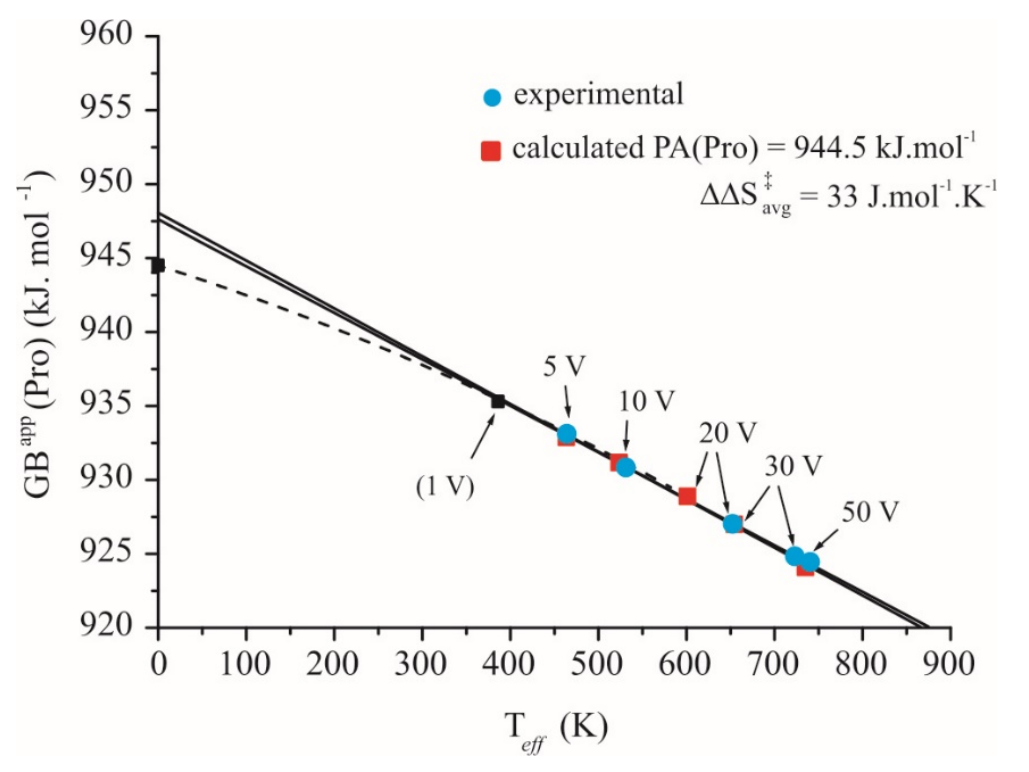

Figure 4. Plot of "GB app(Pro) vs. Teff" determined for different CID conditions ( $(\bullet)$ experimental curve; ( $\mathbf{\square}$ ) calculated by MassKinetics software (parameters Table 1 are used for calculation). Calculated point at $1 \mathrm{~V}$ and PA value used in MassKinetics software are also indicated with black squares and polynomial fit with dotted line. 


\section{Effect of the different parameters used for calculations}

In this work, the effects of the "relative" intrinsic thermo-kinetic properties $(\triangle \mathrm{PA}$, $\Delta \Delta \mathrm{S}^{\ddagger}$ avg) used for simulations modelled by the RRKM-based MassKinetics program are discussed. "Non-relative" parameters like $\mathrm{E}_{0}\left(\mathrm{ProH}^{+}\right)$and $\Delta \mathrm{S}^{\ddagger}\left(\mathrm{ProH}^{+}\right)$as well as "transferred collisional energy" parameters like collisional efficiency, average number of collisions and initial internal energy reached in the ion source prior collisional activation into the collision cell are also investigated. These results are presented in the supplementary material and enable to identify the parameters with the largest influence on the PA(Pro) and $\mathrm{T}_{\text {eff }}$ measurements. It indeed appears that $\mathrm{PA}(\mathrm{Pro})$ depends mostly on the $\Delta \mathrm{S}^{\ddagger}\left(\mathrm{B}_{\mathrm{i}} \mathrm{H}^{+}\right)$ value which is defined herein with a large inaccuracy of $\pm 40 \mathrm{~J} \cdot \mathrm{mol}^{-1} \cdot \mathrm{K}^{-1}$ (see supplementary material Fig. S2(d)).

These simulations do not allow the experimental determination of the $\mathrm{E}_{0}\left(\mathrm{ProH}^{+}\right)$and $\Delta \mathrm{S}^{\ddagger}\left(\mathrm{ProH}^{+}\right)$values of proline. This is mostly due to not-fully controlled operational conditions even if still adequate to kinetic method measurements (multiple collisions, noncalibrated collision pressure and use of a tripe quadrupole). Using a guided ion beam mass spectrometer (GIBMS) would allow to measure $\mathrm{E}_{0}\left(\mathrm{ProH}^{+}\right)$because of well-controlled instrumental parameters (known and lower pressure value, extrapolation to zero collision, better control of the kinetic energy distribution and better transition state description via orbiting transition state).$^{18}$ Because of the large $\Delta \Delta \mathrm{S}^{\ddagger}$ value, the use of hindered rotors would have certainly been necessary to access to $\Delta \mathrm{S}^{\ddagger}\left(\mathrm{ProH}^{+}\right)$.

In the same way, the parameter with the largest effect on the effective temperature is the chosen value for $\Delta \mathrm{S}^{\ddagger}\left(\mathrm{B}_{\mathrm{i}} \mathrm{H}^{+}\right)$. This is coherent with the fact that $\mathrm{T}_{\text {eff }}$ corresponds to the transition state temperature as mentioned by Laskin and Futrell. ${ }^{44}$ However, the shift of the curves to smaller $T_{\text {eff }}$ with an increase of $\Delta \mathrm{S}^{\ddagger}\left(\mathrm{B}_{\mathrm{i}} \mathrm{H}^{+}\right)$may be compensated by an increase of the collisional efficiency value or a higher $\mathrm{E}_{0}\left(\mathrm{ProH}^{+}\right)$value (see supplementary material Fig. S2). Nevertheless, large variations of the collision efficiency do not bring any modification of the slope and $\mathrm{Y}$-intercept for $\mathrm{T}_{\text {eff }}=0 \mathrm{~K}$. Moreover, an increase of the average number of collisions by a factor of five does not change significantly the calculated effective temperature (see supplementary material Fig. S3 (a)). This is due to the fact that, for a small system, each collision is efficient and, as a consequence, the heterodimer is decomposed prior to a second collision.

For this example, the experimental and calculated $\Delta \Delta \mathrm{S}^{\ddagger}$ avg values obtained using MassKinetics software are almost similar $\left(\Delta \Delta \mathrm{S}_{\text {avg }}^{\ddagger}=31 \mathrm{~J} \mathrm{~mol}^{-1} \cdot \mathrm{K}^{-1}, \Delta \Delta \mathrm{S}_{\text {avg }}^{\ddagger}=33 \mathrm{~J} \cdot \mathrm{mol}^{-}\right.$ ${ }^{1} \cdot \mathrm{K}^{-1}$, respectively). The slopes of the "GB ${ }^{\text {app }} v s$. $\mathrm{T}_{\text {eff" }}$ " curves only depend on the $\Delta \Delta \mathrm{S}_{\text {avg }}^{\ddagger}$ value used for simulations and all others studied parameters have no effect (Fig S2(a) in supporting information). Herein, $\Delta \Delta \mathrm{S}^{\ddagger}$ avg is given at $600 \mathrm{~K}$ instead of $400 \mathrm{~K}^{36}$ or $298 \mathrm{~K}^{41 \text {, }}$ ${ }^{43}$ used for previous simulation studies. Furthermore, as reported, the kinetic method conditions are non-equilibrium, and as a consequence, the temperature for calculation of $\Delta \Delta \mathrm{S}_{\text {avg(T) }}^{\ddagger}$ is arbitrary. ${ }^{43}$ The $\Delta \Delta \mathrm{S}_{\text {avg }}^{\ddagger}$ value is related to the effective temperature defined in Equ. 2. Thus, the value of $600 \mathrm{~K}$ is chosen here because it is close to the mean effective temperature derived from kinetic method plots in this study. Nevertheless, this choice is not accurate and $\Delta \Delta \mathrm{S}_{\text {app }}^{\ddagger}$ is not equal to $\Delta \Delta \mathrm{S}^{\dagger}{ }_{\text {avg(T=Teff) }}{ }^{42} \mathrm{Using} \Delta \Delta \mathrm{S}^{\ddagger}{ }_{\text {avg(298 K })}=25 \mathrm{~J} \mathrm{~mol}^{-}$ ${ }^{1} \cdot \mathrm{K}^{-1}$ or $\Delta \Delta \mathrm{S}^{\ddagger}$ avg $(400 \mathrm{~K})=29 \mathrm{~J} \cdot \mathrm{mol}^{-1} \cdot \mathrm{K}^{-1}$ or $\Delta \Delta \mathrm{S}^{\ddagger}{ }_{\text {avg }(600 \mathrm{~K})}=33 \mathrm{~J} \cdot \mathrm{mol}^{-1} \cdot \mathrm{K}^{-1}$ leads to similar simulations. 
As discussed by Drahos and Vékey ${ }^{41}$ and also by Ervin and Armentrout, ${ }^{43}$ the accuracy of experimental values obtained by "relative methods" mainly depends on the accuracy of the $\mathrm{PA}\left(\mathrm{B}_{\mathrm{i}}\right)$ values used as references bases and a systematic error of $\pm 5 \mathrm{~kJ} \cdot \mathrm{mol}^{-1}( \pm 2 \sigma)$ may be considered (for $\Delta \Delta \mathrm{S}^{\dagger}$ avg $<35 \mathrm{~J} \cdot \mathrm{mol}^{-1} \cdot \mathrm{K}^{-1}$ ). Errors in the abundance ratio measurements $\left( \pm 2 \mathrm{~kJ} \mathrm{~mol}^{-1}\right.$ is considered herein) and non-linearity of the kinetic method plots are also included in these errors. This uncertainty must be taken into account for all experimental measurements as well as for simulation results obtained with MassKinetics. For $\Delta \Delta \mathrm{S}^{*}$ avg values, an error of $\pm 10 \mathrm{~J} \cdot \mathrm{mol}^{-1} \cdot \mathrm{K}^{-1}$ is also added for all relative measurements or calculation results. As a conclusion from RRKM simulations $\mathrm{PA}($ Pro $)=944.5 \pm 5 \mathrm{~kJ} \cdot \mathrm{mol}^{-1}$ and $\Delta \Delta \mathrm{S}^{+}$avg $(600 \mathrm{~K})=33 \pm 10 \mathrm{~J} \cdot \mathrm{mol}^{-1} \cdot \mathrm{K}^{-1}$ values were obtained. This PA value obtained by RRKM modeling is closer to the reported theoretical values $\left(937 \pm 8,{ }^{50} 931.8,{ }^{51} 935.0\right.$ and $934.1^{52}$ $\mathrm{kJ} . \mathrm{mol}^{-1}$ ) and $935.1 \mathrm{~kJ} . \mathrm{mol}^{-1}$ (this work)) compared to the experimental one $\left(947.5 \mathrm{~kJ}^{-\mathrm{mol}^{-}}\right.$ $\left.{ }^{1}\right)$. Nevertheless, the difference between experiment and recent theoretical calculations remains of $10 \mathrm{~kJ} \cdot \mathrm{mol}^{-1}$.

\section{Calculation of the effective temperature}

The effective temperatures derived from the slopes of the experimental curves (Fig. 3(a)) and from the calculated curves (Fig. 3(b)) are reported and compared Table 2 and Fig. 5 (denoted experimental and model 1, respectively).

Table 2. $\mathrm{T}_{\text {eff }}$ as a function of Elab for the protonated proline-amine heterodimers obtained from experimental curves and from calculation using the two models discussed in the text (the parameters of Table 1 are used for calculation).

\begin{tabular}{lccc}
\hline \multicolumn{1}{c}{ Elab (V) } & $\mathbf{5}$ & $\mathbf{3 0}$ & $\mathbf{1 0 0}$ \\
& & $\mathbf{T}_{\text {eff }}(\mathbf{K})$ \\
\hline (1) Pyridine (Pyr) & 445 & 700 & 945 \\
(2) Cyclohexylamine (Cyclo) & 445 & 670 & 900 \\
(3) 3-Picoline (Pico) & 410 & 660 & 980 \\
(4) 4-Vinylpyridine & 410 & 665 & 990 \\
(5) 4-Picoline & $(380)$ & $(760)$ & $(1090)$ \\
(6) Pyrrolidine & $(385)$ & $(525)$ & $(1200)$ \\
\hline Model 1 $^{\mathrm{a}}$ (simulated slopes) & $\mathbf{4 7 0}$ & $\mathbf{6 5 7}$ & $\mathbf{8 2 0}$ \\
\hline Model 2 $^{\mathrm{b}}$ (average 1+2+3+4) & $\mathbf{4 2 5}$ & $\mathbf{6 7 5}$ & $\mathbf{9 5 5}$ \\
\hline Experimental (slopes) & $\mathbf{4 6 4}$ & $\mathbf{7 2 3}$ & $\mathbf{8 2 5}$ \\
\hline
\end{tabular}

${ }^{a}$ Model 1 : slopes of the calculated curves " $\ln \left[\mathrm{I}\left(\mathrm{B}_{\mathrm{i}} \mathrm{H}^{+}\right) /\left(\mathrm{ProH}^{+}\right)\right]$ vs. PA $\left(\mathrm{B}_{\mathrm{i}}\right)$ " from Fig. 3(b);

${ }^{\mathrm{b}}$ Model 2: which characteristic temperature leads to the same $\left(\mathrm{I}_{\mathrm{i}} \mathrm{H}^{+}\right) / \mathrm{I}\left(\mathrm{ProH}^{+}\right)$ratio than the one calculated in model 1 ? (Measured above the smaller critical energy of the two competitive processes). 


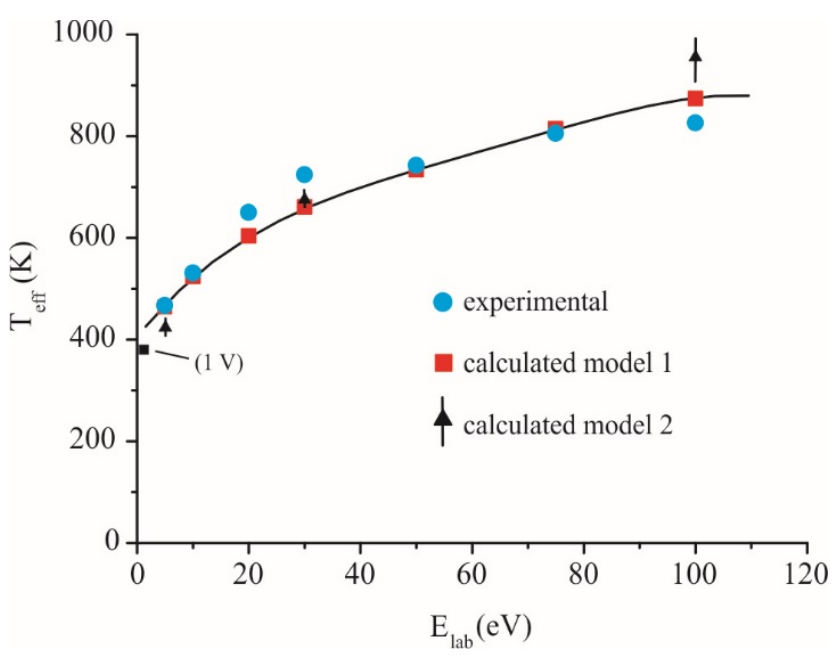

Figure 5. $\mathrm{T}_{\text {eff }} v s$. $\mathrm{E}_{\text {lab }}$ curves obtained from $(\bullet)$ experimental measurements (slopes of the

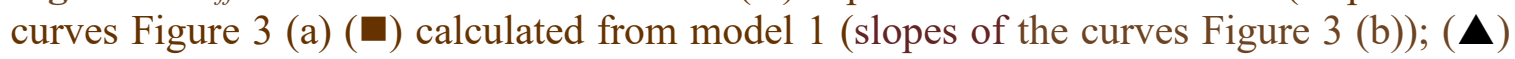
average value calculated from model 2 (Table 2). The black square corresponds to calculated $\mathrm{T}_{\text {eff }}$ at $1 \mathrm{~V}$ (model 1$)$.

During collisional process, a fraction of the kinetic energy of the ion is converted into internal energy. The curve ' $d$ ' (Fig. 6) is the internal energy distribution of the precursor ion calculated after the collision cell H2. A "hypothetic distribution", corresponding to the collision activation of the survival precursor ions where no decomposition in the gas cell is considered, is called curve 'dd'. This curve is calculated by the change of the critical energy with a high hypothetic value in MassKinetics software (e.g., $\mathrm{E}_{0}=10 \mathrm{eV}$ ). In MassKinetics software, the real number of collisions is accurately described by a "Poisson" distribution $(37 \%, 37 \%, 18 \%$, and $8 \%$ for $0,1,2$ and 3 collisions, respectively, with an average of one collision). However, multiple-collision processes are unexpected for the precursor ions because a large part is decomposed after the first collision prior to consecutive collisions. Thus, the maximum energy transferred is related to the center of mass energy $E_{C M}=m_{A r} /\left(m_{A r}+m_{i o n}\right) E_{\text {lab }}$ which corresponds to an increase of $5.1 \mathrm{eV}$ for [Pro $\left.\mathrm{H}^{+} \mathrm{Pyr}\right]$ heterodimer and $\mathrm{E}_{\mathrm{lab}}=30 \mathrm{eV}$ (Fig. 6).

As expected, the internal energy distribution of the decomposing population (pink area, Fig. 6) is not a thermal-like (Maxwell-Boltzmann) distribution. To estimate its effective temperature a somewhat similar approach than that proposed by Drahos and Vékey ${ }^{47}$ for metastable decompositions is proposed (denoted model 2). Then, the energy calibration of the collision cell is made by a similar way to that previously proposed for the energy calibration of an ESI source ${ }^{17}$. So, the entrance of the collision cell is assumed to be a new ion source and the calibration of the collision cell is made like the calibration of an ESI source where $\mathrm{T}_{\text {eff }}$ is measured as $\mathrm{T}_{\text {char }}$. From this approach, the effective temperature may be defined as related to the question: which characteristic temperature leads to the same $\left(\mathrm{I}_{\mathrm{i}} \mathrm{H}^{+}\right) / \mathrm{I}\left(\mathrm{ProH}^{+}\right)$ratio than the one experimentally observed? For convenience, comparison to calculated ratio from model 1 instead of those of experimental is used to avoid deviations due to experimental errors measurements and systematic errors due to the 
inaccuracy values of the reference bases. As proposed by Drahos and Vékey for metastable decompositions ${ }^{47}$ this temperature is measured above the smaller critical energy of the two competitive processes (not always $\mathrm{E}_{0}\left(\mathrm{ProH}^{+}\right)$) because only the excess energy is considered. Nevertheless, two differences exist between the energy calibration of the source $\left(\mathrm{T}_{\text {char }}\right)$ and that of the collision cell $\left(\mathrm{T}_{\text {eff }}\right)$. First, the characteristic temperature is related to a "thermal-like" internal energy distribution due to the slow heating regime occurring for multi-collisional activation into an ESI source whereas for the effective temperature a single collision is involved for the decomposition into the gas cell. The second difference is related to the decomposition time window which plays an important role in the kinetic shift (ks). For CID processes, the time to cross the hexapole $\mathrm{H} 2$, and as a consequence the time to decompose, depends on the applied collisional energies $\left(\mathrm{E}_{\mathrm{lab}}\right)$. Thus, different kinetic shifts and different threshold energies $\left(\mathrm{E}_{\text {thres }}=\mathrm{E}_{0}+\mathrm{ks}\right)$ are taken into account for the different parts of the mass spectrometer. For instance, the time to cross "H0 + Q1" is equal to $190 \mu$ s and the corresponding $\mathrm{E}_{\text {thres }}(\mathrm{C})$ is equal to $1.62 \mathrm{eV}$. For $\mathrm{E}_{\text {lab }}=$ $30 \mathrm{eV}$ in $\mathrm{H} 2$, the corresponding decomposition time is $17 \mu \mathrm{s}$ and $\mathrm{E}_{\text {thres }}(\mathrm{D})$ is equal to 1.89 eV (Fig. 2).

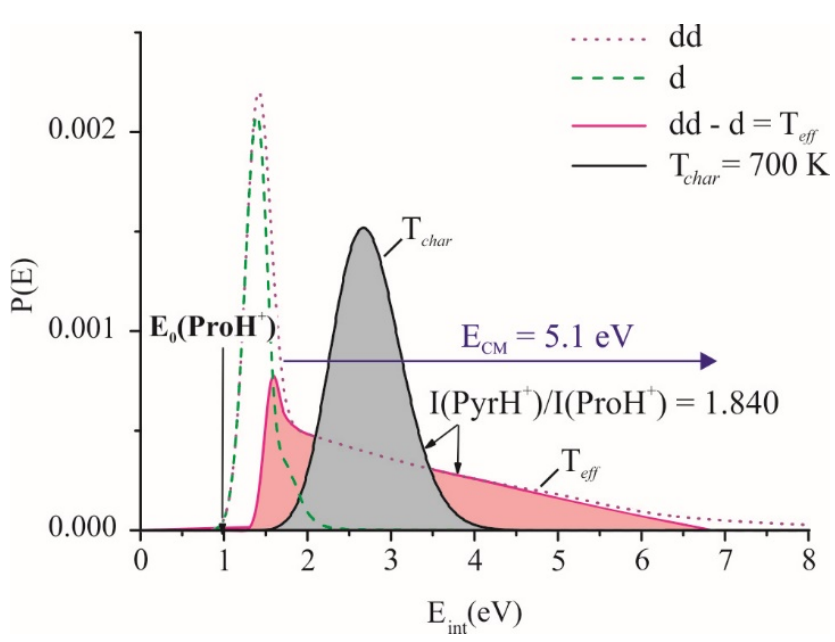

Figure 6. Internal energy distributions of the precursor ions calculated at different points of the mass spectrometer ('d' at point $\mathrm{D}$, end of the collision cell). 'dd' is the resulting curve of collisional activation if no decomposition occurs into the gas cell. 'dd'- ' $\mathrm{d}$ ' is the decomposing population into the gas cell. Calculated $\mathrm{T}_{\text {eff }}$ as a $\mathrm{T}_{\text {char }}$ (model 2) gives the same $\left[\mathrm{I}\left(\mathrm{B}_{\mathrm{i}} \mathrm{H}^{+}\right) / \mathrm{I}\left(\mathrm{ProH}^{+}\right)\right]$ratio than 'dd'-' $\mathrm{d}$ ' population (the pink area is the $\mathrm{T}_{\text {eff }}$ internal energy distribution considering that activated ions are decomposed prior to a second collision).

An average effective temperature is obtained from the slopes of the experimental curves "ln $\left.\left(\mathrm{I}_{\mathrm{i}} \mathrm{H}^{+}\right) / \mathrm{I}\left(\mathrm{ProH}^{+}\right)\right) v s . \mathrm{PA}\left(\mathrm{B}_{\mathrm{i}}\right)$ " (using different heterodimers). Note that using the model 2 , an effective temperature may be calculated for each protonated heterodimer. All these effective temperatures and the average measurement for four heterodimers (1 to 4), are reported in Table 3. The heterodimers (5) and (6) are not taken into account for the average measurement because they are located close to the isokinetic point (Fig. 3(a)). As a consequence, the large uncertainty of the calculated effective temperature is due to the very small variations of $\mathrm{I}\left(\mathrm{Bi}_{\mathrm{i}} \mathrm{H}^{+}\right) / \mathrm{I}\left(\mathrm{ProH}^{+}\right)$ratio. For instance, in the case of system (6), the 
calculated $\ln \left(\mathrm{I}\left(4-\mathrm{picoH}^{+}\right) / \mathrm{I}\left(\mathrm{ProH}^{+}\right)\right)$is equal to $3.73,3.73$, and 3.84 for $5 \mathrm{~V}, 30 \mathrm{~V}$ and 100 $\mathrm{V}$, respectively, and the difference of effective temperatures measured $(380 \mathrm{~K}, 760 \mathrm{~K}$ and $1090 \mathrm{~K}$ ) is only due to different kinetic shifts. Note that, as reported by Armentrout, ${ }^{43}$ the "isokinetic point" which is also called "isothermal point" does not correspond to a constant temperature. He proposed to call this point the "pseudo-isoequilibrium point" because it is the point at which the apparent equilibrium constant $\mathrm{K}=k_{\mathrm{i}} / k_{0}$ is the same for all effective temperatures. This model 2 is in good agreement with the literature describing that the effective temperature depends on decomposition time. ${ }^{14,35,44}$ Nevertheless, from Table 3 an expected effect of $\Delta \mathrm{E}$ on $\mathrm{T}_{e f f}{ }^{35}$ is not observed due to a small variation of $\Delta \mathrm{E}$. The case of an increase of DOF is more complex. From previous studies ${ }^{42,44}$ an increase of DOF will lead to an increase of effective temperature. Using the model 2, a single simulation leads to the following results: $\mathrm{T}_{\text {char }}=700 \mathrm{~K}$ and $\mathrm{T}_{\text {eff }}=700 \mathrm{~K}$ (DOF of $90, \mathrm{Vc}=10 \mathrm{~V}$ and $\left.\mathrm{E}_{\mathrm{lab}}=30 \mathrm{eV}\right) ; \mathrm{T}_{\text {char }}=570 \mathrm{~K}$ and $\mathrm{T}_{\text {eff }}=630 \mathrm{~K}$ (DOF of 140). Thus, in this example a small decrease of $\mathrm{T}_{\text {eff }}$ with an increase of DOF is observed.

However, it should be noted that for simplification, model 1 and model 2 do not take into account the variation of $\mathrm{E}_{0}\left(\mathrm{ProH}^{+}\right), \Delta \Delta \mathrm{S}^{*}$ avg and the variation of DOF with the nature of the studied heterodimer and, as a consequence, an exact fit of experimental measurements is not expected. Nevertheless, these results evidence that $T_{\text {eff }}$ parameter in Equ. 3 is not very different to a characteristic temperature.

\section{Conclusion}

For the studied example, only well-defined proton affinity value (PA(Pro) $=944.5 \pm 5$ $\left.\mathrm{kJ} . \mathrm{mol}^{-1}\right)$ and activation entropy difference value $\left(\Delta \Delta \mathrm{S}^{\ddagger}{ }_{\text {avg(600K) }}=33 \pm 10 \mathrm{~J} \cdot \mathrm{mol}^{-1} \cdot \mathrm{K}^{-1}\right)$ allow an accurate fit of the experimental curves "GB ${ }^{\text {app }}$ (Pro) vs. Teff". The inaccuracy of the PA determination using MassKinetics modeling is mainly due to the unknown "absolute values" which cannot be accessed by RRKM simulations like $\mathrm{E}_{0}\left(\mathrm{ProH}^{+}\right)$and $\Delta \mathrm{S}^{\ddagger}\left(\mathrm{ProH}^{+}\right)$. It is also due to inaccuracy of references amine values used. Nevertheless, it should be emphasized that the PA value obtained by RRKM modeling is closer to the most recent value obtained by calculations $\mathrm{PA}(\mathrm{Pro})=935.0$ and $934.1^{52} \mathrm{~kJ} \cdot \mathrm{mol}^{-1}$ and $935.1 \mathrm{~kJ} \cdot \mathrm{mol}^{-1}$ (this work)) compared to that experimentally measured by alternative kinetic methods $\left(\mathrm{PA}(\mathrm{Pro})=947.5 \pm 5 \mathrm{~kJ} \cdot \mathrm{mol}^{-1}\right)$.

No alternative methods and effective temperature parameter are necessary for MassKinetics calculations because only the $\left(\mathrm{I}_{\mathrm{i}} \mathrm{H}^{+}\right) / \mathrm{I}\left(\mathrm{ProH}^{+}\right)$ratio and the survival yield are required to fit experimental results. However, the effective temperatures measured from calculated and experimental curves are close. The internal energy distribution of the ions which are decomposed in the gas cell is not a thermal-like distribution. Nevertheless, for a defined decomposition time, the "temperature calibration" of the collision cell by a characteristic temperature shows that this decomposing population characterizes the effective temperature $\left(\mathrm{T}_{\text {eff }}\right)$, as previously suggested.

Acknowledgements

This work was granted access to the HPC resources of the HPCaVe centre at UPMCSorbonne Université and from GENCI-[IDRIS] (Grant 2018-A0030810312).

Funding statement or Declaration of conflicting interests 
The authors declare no conflict of interests.

\section{References}

1. Dunbar RC. Kinetics of Thermal Unimolecular Dissociation by Ambient Infrared Radiation. J Phys Chem 1994; 98: 8705-8712. DOI: 10.1021/j100086a020.

2. Thoelmann D, Tonner DS and McMahon TB. Spontaneous Unimolecular Dissociation of Small Cluster Ions, $(\mathrm{H} 3 \mathrm{O}+) \mathrm{Ln}$ and $\mathrm{Cl}-(\mathrm{H} 2 \mathrm{O}) \mathrm{n}(\mathrm{n}=2-4)$, under Fourier Transform Ion Cyclotron Resonance Conditions. J Phys Chem 1994; 98: 2002-2004. DOI: $10.1021 / \mathrm{j} 100059 \mathrm{a} 002$.

3. Dunbar RC. BIRD (blackbody infrared radiative dissociation): Evolution, principles, and applications. Mass Spectrom Rev 2004; 23: 127-158. DOI: doi:10.1002/mas.10074.

4. Price WD, Schnier PD and Williams ER. Binding Energies of the Proton-Bound Amino Acid Dimers Gly·Gly, Ala·Ala, Gly·Ala, and Lys·Lys Measured by Blackbody Infrared Radiative Dissociation. $J$ Phys Chem $B$ 1997; 101: 664-673. DOI: 10.1021/jp9628702.

5. Gabelica V, Karas M and De Pauw E. Calibration of Ion Effective Temperatures Achieved by Resonant Activation in a Quadrupole Ion Trap. Anal Chem 2003; 75: 51525159. DOI: $10.1021 / \mathrm{ac034473a.}$

6. Schnier PD, Jurchen JC and Williams ER. The Effective Temperature of Peptide Ions Dissociated by Sustained Off-Resonance Irradiation Collisional Activation in Fourier Transform Mass Spectrometry. $J$ Phys Chem $B$ 1999; 103: 737-745. DOI: 10.1021/jp9833193.

7. Bayat $\mathrm{P}$, Gatineau D, Lesage D, et al. Investigating binding energies of host-guest complexes in the gas-phase using low-energy collision induced dissociation. to be submitted to PCCP July 2018.

8. Cooks GR, Jeffrey PS, Tapio K, et al. Thermochemical determinations by the kinetic method. Mass Spectrom Rev 1994; 13: 287-339. DOI: doi:10.1002/mas.1280130402.

9. Lindemann FA, Arrhenius S, Langmuir I, et al. Discussion on "the radiation theory of chemical action". Transactions of the Faraday Society 1922; 17: 598-606. 10.1039/TF9221700598. DOI: 10.1039/tf9221700598.

10. Levine RD. Kinetics of Unimolecular Breakdown. VIII. The LindemannHinshelwood Mechanism. J Chem Phys 1968; 48: 4556-4560. DOI: 10.1063/1.1668027.

11. Marcus RA and Rice OK. The Kinetics of the Recombination of Methyl Radicals and Iodine Atoms. J Phys Chem 1951; 55: 894-908. DOI: 10.1021/j150489a013.

12. Rosenstock HM, Wallenstein MB, Wahrhaftig AL, et al. Absolute Rate Theory for Isolated Systems and the Mass Spectra of Polyatomic Molecules. Proceedings of the National Academy of Sciences of the United States of America 1952; 38: 667-678. 
13. Collette $\mathrm{C}$ and De Pauw E. Calibration of the internal energy distribution of ions produced by electrospray. Rapid Commun Mass Spectrom 1998; 12: 165-170. DOI: 10.1002/(sici)1097-0231(19980227)12:4<165::aid-rcm140>3.0.co;2-1.

14. Drahos L, Heeren Ron MA, Collette C, et al. Thermal energy distribution observed in electrospray ionization. $J$ Mass Spectrom 1999; 34: 1373-1379. DOI: 10.1002/(sici)1096-9888(199912)34:12<1373::aid-jms907>3.0.co;2-\#.

15. Pak A, Lesage D, Gimbert $Y$, et al. Internal energy distribution of peptides in electrospray ionization : ESI and collision-induced dissociation spectra calculation. J Mass Spectrom 2007; 43: 447-455. DOI: 10.1002/jms.1330.

16. Gabelica $V$ and De Pauw E. Internal energy and fragmentation of ions produced in electrospray sources. Mass Spectrom Rev 2004; 24: 566-587. DOI: 10.1002/mas.20027.

17. Naban-Maillet J, Lesage D, Bossée A, et al. Internal energy distribution in electrospray ionization. J Mass Spectrom 2005; 40: 1-8. DOI: doi:10.1002/jms. 773.

18. Carpenter JE, McNary CP, Furin A, et al. How Hot are Your Ions Really? A Threshold Collision-Induced Dissociation Study of Substituted Benzylpyridinium "Thermometer" Ions. J Am Soc Mass Spectrom 2017; 28: 1876-1888. journal article. DOI: 10.1007/s13361-017-1693-0.

19. Touboul D, Jecklin MC and Zenobi R. Ion internal energy distributions validate the charge residue model for small molecule ion formation by spray methods. Rapid Commun Mass Spectrom 2008; 22: 1062-1068. DOI: doi:10.1002/rcm.3469.

20. Dumlao M, Khairallah GN and Donald WA. Internal Energy Deposition in Dielectric Barrier Discharge Ionization is Significantly Lower than in Direct Analysis in Real-Time Mass Spectrometry. Aust J Chem 2017; 70: 1219-1226. DOI: 10.1071/CH17440.

21. Hampton CY, Silvestri CJ, Forbes TP, et al. Comparison of the internal energy deposition of venturi-assisted electrospray ionization and a venturi-assisted array of micromachined ultrasonic electrosprays (AMUSE). J Am Soc Mass Spectrom 2008; 19: 1320-1329. DOI: 10.1016/j.jasms.2008.06.012.

22. Ichou F, Lesage D, Machuron-Mandard X, et al. Collision cell pressure effect on CID spectra pattern using triple quadrupole instruments: a RRKM modeling. $J$ Mass Spectrom 2013; 48: 179-186. DOI: doi:10.1002/jms.3143.

23. Gatineau $\mathrm{D}$, Lesage $\mathrm{D}$, Clavier $\mathrm{H}$, et al. Bond dissociation energies of carbonyl gold complexes: a new descriptor of ligand effects in gold(i) complexes? Dalton Trans 2018; 47: 15497-15505. 10.1039/C8DT03721C. DOI: 10.1039/c8dt03721c.

24. Ichou F, Schwarzenberg A, Lesage D, et al. Comparison of the activation time effects and the internal energy distributions for the CID, PQD and HCD excitation modes. J Mass Spectrom 2014; 49: 498-508. DOI: doi:10.1002/jms.3365.

25. Greisch JF, Gabelica V, Remacle F, et al. Thermometer ions for matrix-enhanced laser desorption/ionization internal energy calibration. Rapid Commun Mass Spectrom 2003; 17: 1847-1854. DOI: 10.1002/rcm.1124. 
26. Picca RA, Calvano CD, Cioffi N, et al. Mechanisms of Nanophase-Induced Desorption in LDI-MS. A Short Review. Nanomaterials 2017; 7: 75. DOI: 10.3390/nano7040075.

27. Luo G, Chen Y, Siuzdak G, et al. Surface Modification and Laser Pulse Length Effects on Internal Energy Transfer in DIOS. J Phys Chem B 2005; 109: 24450-24456. DOI: $10.1021 /$ jp054311d.

28. Cooks RG and Kruger TL. Intrinsic basicity determination using metastable ions. $J$ Am Chem Soc 1977; 99: 1279-1281. DOI: 10.1021/ja00446a059.

29. McLuckey SA, Cameron D and Cooks RG. Proton affinities from dissociations of proton-bound dimers. J Am Chem Soc 1981; 103: 1313-1317. DOI: 10.1021/ja00396a001.

30. Bartmess JE, Scott JA and McIver RT, Jr. Scale of Acidities in the Gas Phase from Methanol to Phenol. J Am Chem Soc 1979; 101: 6046-6056. DOI: 10.1021/ja00514a030.

31. Armentrout PB. Is the kinetic method a thermodynamic method? J Mass Spectrom 1999; 34: 74-78. DOI: doi:10.1002/(SICI)1096-9888(199902)34:2<74::AIDJMS794>3.0.CO;2-6.

32. $\mathrm{Wu} \mathrm{Z}$ and Fenselau C. Proton affinities of polyglycines assessed by using the kinetic method. J Am Soc Mass Spectrom 1992; 3: 863-866. DOI: 10.1016/10440305(92)80011-9.

33. Armentrout PB. Entropy measurements and the kinetic method: A statistically meaningful approach. J Am Soc Mass Spectrom 2000; 11:371-379. DOI: 10.1016/s10440305(00)00102-1.

34. Nold MJ, Cerda BA and Wesdemiotis C. Proton affinities of the N- and C-terminal segments arising upon the dissociation of the amide bond in protonated peptides. $J \mathrm{Am} \mathrm{Soc}$ Mass Spectrom 1999; 10: 1-8. DOI: 10.1016/s1044-0305(98)00120-2.

35. Ervin KM. Microcanonical analysis of the kinetic method. The meaning of the "apparent entropy". J Am Soc Mass Spectrom 2002; 13: 435-452. journal article. DOI: 10.1016/s1044-0305(02)00357-4.

36. Drahos L and Vékey K. Entropy evaluation using the kinetic method: is it feasible? J Mass Spectrom 2003; 38: 1025-1042. DOI: 10.1002/jms.538.

37. Drahos L and Vékey K. MassKinetics: a theoretical model of mass spectra incorporating physical processes, reaction kinetics and mathematical descriptions. J Mass Spectrom 2001; 36: 237-263. DOI: doi:10.1002/jms.142.

38. Bouchoux G. Evaluation of the protonation thermochemistry obtained by the extended kinetic method. $J$ Mass Spectrom 2006; 41: 1006-1013. DOI: doi:10.1002/jms. 1055.

39. Bouchoux G. Microcanonical Modeling of the Thermokinetic Method. $J$ Phys Chem A 2006; 110: 8259-8265. DOI: 10.1021/jp055199m.

40. Bouchoux G, Sablier M and Berruyer-Penaud F. Obtaining thermochemical data by the extended kinetic method. $J$ Mass Spectrom 2004; 39: 986-997. DOI: 10.1002/jms.680. 
41. Drahos L, Peltz C and Vékey K. Accuracy of enthalpy and entropy determination using the kinetic method: are we approaching a consensus? J Mass Spectrom 2004; 39: 1016-1024. DOI: 10.1002/jms.683.

42. Ervin KM. Microcanonical analysis of the kinetic method.: The meaning of the "effective temperature". Int J Mass Spectrom 2000; 195-196: 271-284. DOI: https://doi.org/10.1016/S1387-3806(99)00176-1.

43. Ervin KM and Armentrout PB. Systematic and random errors in ion affinities and activation entropies from the extended kinetic method. J Mass Spectrom 2004; 39: 10041015. DOI: doi: $10.1002 / \mathrm{jms} .682$.

44. Laskin J and Futrell JH. The Theoretical Basis of the Kinetic Method from the Point of View of Finite Heat Bath Theory. $J$ Phys Chem A 2000; 104: 8829-8837. DOI: 10.1021/jp001556b.

45. Wesdemiotis C. Entropy considerations in kinetic method experiments. $J$ Mass Spectrom 2004; 39: 998-1003. DOI: 10.1002/jms.681.

46. Bourgoin-Voillard S, Afonso C, Lesage D, et al. Critical Evaluation of Kinetic Method Measurements: Possible Origins of Nonlinear Effects. J Am Soc Mass Spectrom 2013; 24: 365-380. DOI: 10.1007/s13361-012-0554-0.

47. Drahos L and Vékey K. How closely related are the effective and the real temperature. J Mass Spectrom 1999; 34: 79-84. DOI: doi:10.1002/(SICI)10969888(199902)34:2<79::AID-JMS793>3.0.CO;2-V.

48. Mezzache S, Bruneleau N, Vekey K, et al. Improved proton affinity measurements for proline and modified prolines using triple quadrupole and ion trap mass spectrometers. J Mass Spectrom 2005; 40: 1300-1308. DOI: 10.1002/jms.905.

49. Linstrom PJ and Mallard WG, Eds, NIST Chemistry WebBook, NIST Standard Reference Database Number 69, Gaithersburg MD, 20899 (July 2018, accessed 07/10/2018) DOI: 10.18434/T4D303.

50. Kuntz AF, Boynton AW, David GA, et al. The proton affinity of proline analogs using the kinetic method with full entropy analysis. J Am Soc Mass Spectrom 2002; 13: 7281. DOI: $10.1016 / \mathrm{s} 1044-0305(01) 00329-4$.

51. Kanchi V and Shin J-W. Kinetic Method Analysis of the Effect of cis- and transHydroxylation on the Proton Affinity of Proline. Aust J Chem 2015; 68: 1518-1523. DOI: $10.1071 / \mathrm{CH} 15047$.

52. Bleiholder C, Suhai S and Paizs B. Revising the Proton Affinity Scale of the Naturally Occurring $\alpha$-Amino Acids. J Am Soc Mass Spectrom 2006; 17: 1275-1281. DOI: https://doi.org/10.1016/j.jasms.2006.05.010.

53. www.chemres.hu/ms/masskinetics/.

54. Gaussian 09, Revision D.01. M. J. Frisch, G. W. Trucks, H. B. Schlegel, et al. Gaussian, Inc. Wallingford CT, 2013.

55. Curtiss LA, Redfern PC and Raghavachari K. Gaussian-4 theory. $J$ Chem Phys 2007; 126: 084108. DOI: 10.1063/1.2436888. 
56. Bouchoux G, Buisson D-A, Bourcier S, et al. Application of the kinetic method to bifunctional bases: ESI tandem quadrupole experiments. Int J Mass Spectrom 2003; 228: 1035-1054. DOI: https://doi.org/10.1016/S1387-3806(03)00219-7.

57. Gatineau D, Memboeuf A, Milet A, et al. Experimental bond dissociation energies of benzylpyridinium thermometer ions determined by threshold-CID and RRKM modeling. Int J Mass Spectrom 2017; 417: 69-75. DOI: 10.1016/j.ijms.2017.03.002.

58. Boggs PT, Byrd RH, Rogers JE, et al. ODRPACK Version 2.01 Software for Weighted Orthogonal Distance Regression. National Institute of Standards and Technology, Gaithersburg, 1992. 